\title{
ESTIMATING RISK AVERSION, RISK-NEUTRAL AND REAL-WORLD DENSITIES USING BRAZILIAN REAL CURRENCY OPTIONS
}

\author{
José FAJARdo * \\ José Renato HaAs Ornelas ${ }^{\dagger}$ \\ Aquiles Rocha de Farias $\ddagger$
}

\begin{abstract}
This paper uses the Liu et al. (2007) approach to estimate the optionimplied Risk-Neutral Densities (RND), real-world density (RWD), and relative risk aversion from the Brazilian Real/US Dollar exchange rate distribution. Our empirical application uses a sample of exchange-traded Brazilian Real currency options from 1999 to 2011. Our estimated value of the relative risk aversion is around 2.7, which is in line with other articles for the Brazilian Economy. Our out-of-sample results showed that the RND has some ability to forecast the Brazilian Real exchange rate, but when we incorporate the risk aversion, the out-of-sample performance improves substantially.
\end{abstract}

Keywords: Relative Risk Aversion; Risk-Neutral Density; Exchange Rate.

\section{Resumo}

Este artigo usa a abordagem de Liu et al. (2007) para estimar a densidade neutra ao risco, densidade do mundo real e a aversão relativa ao risco da distribuição da taxa de câmbio Dólar/Real. Na estimação foi utilizada uma amostra de opções Dólar/Real negociadas em bolsa entre 1999 e 2011. O valor estimado para a aversão relativa ao risco foi de 2,7, em linha com outros artigos que também estimaram este parâmetro para a economia brasileira. A avaliação fora da amostra mostrou que a densidade neutra ao risco possui alguma habilidade para prever a taxa de câmbio Dólar/Real, mas quando o parâmetro de aversão ao risco é incorporado, a performance fora da amostra melhora substancialmente.

Palavras-chave: Aversão Relativa ao Risco; Densidade Neutra ao Risco; Taxa de Câmbio.

JEL classification: C53, C13, G17, F31

\footnotetext{
* Brazilian School of Public and Business Administration, Getulio Vargas Foundation, Praia de Botafogo 190, 22253900 - Rio de Janeiro, RJ, Brazil. E-mail: jose.fajardo@fgv.br

† Banco Central do Brasil. E-mail: jrenato.ornelas@bcb.gov.br

‡ Banco Central do Brasil. E-mail: aquiles.farias@bcb.gov.br

The views expressed in this work are those of the authors and do not necessarily reflect those of the Banco Central or its members
} 


\section{Introdution}

Extracting market expectations is one of the most important tasks in economics and finance. Market expectations on financial variables may influence macroeconomic policy decisions. It can be also useful for corporate and financial institutions decision making. Many techniques have been applied in order to extract market expectations, among them building Risk-Neutral Density (RND) from options prices is one of the most used. In this sense the papers of Shimko (1993), Rubinstein (1994) and Jackwerth \& Rubinstein (1996) were the first to empirically obtain RND. Using option-implied RND, one can calculate, for example, the probability that exchange rate will stay inside a specific range of values. Any empirical application in finance that that requires densities forecasts may also take advantage of Risk-neutral densities.

On the other hand, many papers had focused its attention on the estimation of the relative risk aversion (RRA) from option prices. Once you have the RND and the subjective density, if these densities are not equal, the risk aversion adjustment indicates the investors' preferences for risk. The first to recover empirically RRA was Jackwerth (2000). He used the historical density as the subjective density. There are other ways to obtain the RRA, as for example the approach introduced by Bliss \& Panigirtzoglou (2004).

Most of the works that have studied RRA estimation have used options on stocks. But, as pointed out by Micu (2005) and Bakshi et al. (2008), it is important to address the same estimation using currency option data in order to obtain a global risk premium.

In this paper we estimate RND from the Brazilian Real/US Dollar (USD/BRL) exchange rate option data and compares with actual exchange rates in order to estimate the relative risk-aversion of investors and also obtain a real-world density for the exchange rate distribution. This is done for a sample of USD/BRL options traded at BM\&F-Bovespa from 1999 to 2011. The RND is estimated using a Mixture of Two Log-Normals distribution and then the real-world density is obtained by means of the Liu et al. (2007) parametric risk-transformations. The relative risk aversion is calculated for the full sample, and is in line with previous studies of the Brazilian economy using stock and consumption data. An out-of-sample goodness-of-fit evaluation is carried out to evaluate the performance of the risk-neutral and real world densities.

Summing up our contributions are: We are the first to calculate RRA parameter for the Brazilian Real Exchange rate. Second, we evaluate the RND and RWD density forecasts for the USD/BRL and obtain a very good out-ofsample fit for the Real World Density, with mixed results for the RND.

The paper is organized as follows: in Section 2 we give an overview of the RND extraction methods. In Section 3 we present the transformation to obtain the RWD. In Section 4 we present our estimation algorithm. In Section 5 we describe our sample data. In Section 6 we present our results and Section 7 concludes.

\section{Risk-Neutral Density (RND)}

Once we have a set of option prices for a specific time to maturity, we can recover the risk-neutral probability distribution (Ross 1976). There are many methods for recovering this RND function implied in option prices. Jackwerth 
(1999) reviews this literature, and classify them into parametric and non-parametric methods.

Parametric methods assume that the risk-neutral distribution can be defined by a limited set of parameters. Once defined the functional form of the distribution, we need to estimate the set of parameters. For instance we can use the Generalized Beta of Second Kind or the Mixture of two log-Normals in order to obtain the RND. Abe et al. (2007) was the only paper so far that analyzed the forecast ability of RND for the Brazilian Real, and used the Generalized Beta of Second Kind.

Non-parametric methods consist of fitting CDFs to observed data by means of more general functions. Among the non-parametric methods are the kernel methods and the maximum-entropy methods. Kernel methods use regressions without specifying the parametric form of the function (for example, see Ait-Sahalia \& Lo 1998). Maximum-entropy methods fit the distribution by minimizing some specific loss function, as we can see in Buchen \& Kelly (1996).

In our paper, we use the Mixture of two Lognormals (M2N) method for recovering the risk-neutral distribution (RND). We will describe this method on Section 4.

\section{Risk Transformations methods}

Once we have a RND of an asset, we may use it to forecast its behavior. However, in many cases the actual behavior of the asset embeds a risk premium, which in the equity market is known as Equity Risk Premium.

For short-term forecasts, this premium is usually small if compared with the volatility of the asset, so we can neglect it, and use just the RND. But for longer term, the size of this premium may be relevant. In this way, if we are trying to forecast over a longer time period, it would be important to use a distribution which includes the risk premium, and this is usually called "realworld" distribution.

Transformations from a risk-neutral density $g$ to a real-world density $h$ can be derived by making assumptions about risk preferences. Liu et al. (2007) assume a representative agent with a power utility function and constant relative risk aversion (RRA) denoted by $c$. The marginal utility is proportional to $x-c$ and the real-world density is given by:

$$
h(x)=\frac{x^{c} g(x)}{\int_{0}^{\infty} y^{c} g(y) d y}
$$

In our paper, we use this transformation for the $\mathrm{M} 2 \mathrm{~N}$ distribution, as can be seen on next section.

\section{Methodology}

We use a Mixture of Log-Normals to model the Risk-Neutral Densities. More specifically, we model the future price of the exchange rate using a mixture of two lognormals densities $g$ :

$$
g\left(x \mid w, F_{1}, \sigma_{1}, F_{2}, \sigma_{2}\right)=w * p d f_{L N}\left(x \mid F_{1}, \sigma_{1}\right)+(1-w) * p d f_{L N}\left(x \mid F_{2}, \sigma_{2}\right)
$$


with

$$
p d f_{\ln (x \mid F, \sigma)}=(x \sigma \sqrt{2 \pi T})^{-1} \exp \left(-\frac{1}{2}\left[\frac{\log (x)-\left(\log (F)-0.5 \sigma^{2} T\right)}{\sigma \sqrt{T}}\right]^{2}\right)
$$

We use the USD future contract exchange rate $F$ to reduce the number of free parameters of the distribution. We do that by making the expectation of the distribution equal to Dollar Future Contract price:

$$
F=w * F_{1}+(1-w) * F_{2}
$$

Therefore, we have a total of five parameters, but only four free parameters. This distribution is able to represent asymmetric and bimodal shapes. The parameters $F_{1}$ and $F_{2}$ are the expectation of the two distributions of the mixture, while the $\sigma$ parameters determine volatility.

The price of an European call option is the weighted average of two Black (1976) call option formulas $C_{B}(F, \sigma, K, r, T)$ :

$$
C\left(F_{i}, \sigma_{i}, w, K, r, T\right)=w C_{B}\left(F_{1}, \sigma_{1}, K, r, T\right)+(1-w) C_{B}\left(F_{2}, \sigma_{2}, K, r, T\right)
$$

We may have used the Garman-Kohlhagen framework in equations 2 to 5 instead of using Black model. In this case, we would have used the foreign interest rate (in the Brazilian market we have a foreign interest rate future contract called DDI) instead of the future exchange rate. However, as the DOL futures are much more liquid than the foreign interest rate futures (DDI), we have decided to use the Black model.

The parameters estimation of the $\mathrm{M} 2 \mathrm{~N}$ was done using an adaptation of the algorithm of Jondeau \& Rockinger $(2001)^{1}$ for the Brazilian Real/U.S. Dollar Exchange rate option characteristics and data. This algorithm estimates parameters by minimizing the squared errors of the theoretical and actual option prices.

Once we have the RND, we calculate the RRA parameter following the Liu et al. (2007) Parametric Risk transformation. As seen on section 3, they consider the real-world density $h$ defined by 1 when there is a representative agent who has constant RRA equal to $c$. If the risk-neutral density $g$ is a single lognormal density then so is $h$. When $g$ is defined by 3 , the two volatility parameters for functions $g$ and $h$ are the same. However, their expected values $F_{1}$ and $F_{2}$, and the weight parameter $w$ are different. For a M2N $g\left(x \mid w, F_{1}, \sigma_{1}, F_{2}, \sigma_{2}\right)$ given by 2 , it is shown by Liu et al. (2007) that the realworld density $h$ is also a Mixture of Lognormals with the following density:

$$
\tilde{g}\left(x \mid w, F_{1}, \sigma_{1}, F_{2}, \sigma_{2}, c\right)=h\left(z \mid w^{\prime}, F_{1}^{\prime}, \sigma_{1}^{\prime}, F_{2}^{\prime}, \sigma_{2}^{\prime}\right)
$$

where the new set of transformed parameter is:

\footnotetext{
${ }^{1}$ The original algorithm of Jondeau and Rockinger is available at the website: http://www.hec.unil.ch/MatlabCodes/rnd.html. Among the changes we have done in the algorithm, we use formula 4 to reduce the number of parameters.
} 


$$
\begin{aligned}
F_{1}^{\prime} & =F_{1} \exp \left(c \sigma_{1}^{2} T\right) \\
F_{2}^{\prime} & =F_{2} \exp \left(c \sigma_{2}^{2} T\right) \\
\frac{1}{w^{\prime}} & =1+\left(\frac{1-w}{w}\right)\left(\frac{F_{2}}{F_{1}}\right)^{c} \exp \left(0.5 T\left(c^{2}-c\right)\left(\sigma_{2}^{2}-\sigma_{1}^{2}\right)\right)
\end{aligned}
$$

It is worth noting that, although the two volatility parameters $\sigma_{1}$ and $\sigma_{2}$ are the same for $g$ and $h$, the standard deviation of the transformed function may be different because the weight parameter $w$ is different. Thus, the RealWorld density and Risk-Neutral Density may have different means, standard deviations and shapes. ${ }^{2}$

The real-world density has a closed-form representation because the cumulative function of the M2N density is simply a weighted combination of cumulative probabilities for the standard normal distribution. However, the calibration of this transformation requires the estimation of the RRA parameter $c$, which ideally should be calculated over a long time series of data.

\section{Dataset}

Our dataset consists of put and call option prices traded at BM\&F Exchange from March 1999 to February 2011. The Brazilian exchange rate derivative market has the liquidity concentrated in short-term contracts, typically the next begin-of-month. Because of this short-term liquidity and also to avoid overlap of data, we took only options with about one month (20 business days $^{3}$ ) to the expiration date. This left us with 143 non-overlapping expiration cycles, since expiration dates are always in the first day of the month. Note that if we had chosen options with a higher time-to-expiration (for instance, two months or one year), we would have fewer non-overlapping expiration cycles and also options with lower liquidity. Therefore, the dataset has 1,460 daily average option prices, with 938 calls and 522 puts. We have built RND with 10.2 options on average.

Besides the USD/BRL Options data, we have collected also data from the future contract of the USD/BRL exchange rate (DOL Futures) and futures contract of Average Rate of One-Day Interbank Deposit (DI Futures), both with expiration at the same date of the respective option. Finally, for each expiration date we collected the USD/BRL spot exchange rate, called PTAX, ${ }^{4}$ which is the underlying asset of both options and DOL futures. It is worth noting that all quotes in this market are done in terms of Brazilian Real per U.S. Dollar, which means that an appreciation (depreciation) of the Brazilian Real decreases (increases) the exchange rate.

We may have problems with the lack of synchronism between the traded time of the option and the DOL and DI Futures, since we are using the average price of the day. This may include some noise in our risk-neutral densities.

\footnotetext{
${ }^{2}$ See, for instance, figure 5 of Bahra (1997).

${ }^{3}$ When we had less than 5 options traded 20 business days before expiration, we used the business day before or after, depending on the liquidity.

${ }^{4}$ The PTAX is the daily average spot exchange rate, calculated by the Central Bank of Brazil. The time period of the PTAX is one month lagged, since it is used to assess the RND and also to calculate the RRA.
} 
However, using the average for both futures and options is the best we can do without having intraday data.

The period of the sample starts just after the end of the almost-fixed exchange rate regime in Brazil. There were various upward shocks in the exchange rate (i.e. devaluation of the Brazilian Real) during the period, including the period of the Brazilian elections in 2002 and the sub-prime crisis of 2008. Apart from these shocks, there is a downward trend in the exchange rate after the overshooting that followed the free-float in 1999, which means appreciation of the Brazilian Real against U.S. Dollar.

\section{Results}

\subsection{Risk-Neutral Distribution Estimation}

We have extracted the risk-neutral densities using the M2N method for the 143 expiration cycles, which are all non-overlapping. For estimation, we minimized the squared errors of the actual option price and the theoretical option price of the Risk-Neutral Distribution. The mean squared error divided by the future exchange rate in our estimation was $0.21 \%$ and the median $0.0251 \%$.

\subsection{Relative Risk Aversion Estimation}

We have calculated a Relative Risk Aversion (RRA) for the full sample using the log-likelihood function as in Liu et al. (2007). This estimation takes the RND parameters estimated last section and then maximize the log-likelihood function with the RRA being the only free parameter. This is done for the 143 expiration cycles, which are all non-overlapping, as seen before. Therefore we have 143 RND $g_{i}$ 's estimated parameters set $\widehat{\theta}_{i}=\left(\widehat{w}, \widehat{F_{1}}, \widehat{\sigma_{1}}, \widehat{F_{2}}, \widehat{\sigma_{2}}\right)$ and aim to maximize the following function:

$$
\sum_{i=1}^{n} \log \left(\tilde{g}\left(P T A X_{i+1} \mid \widehat{\theta}_{i}, c\right)\right)
$$

The estimated RRA parameter c using equation 8 is $2.6959^{5}$ and the $p$ value of the null hypothesis of this parameter being equal to zero is $7.45 \%$, so that there is evidence of some risk premium for the Brazilian Real.

This is in line with previous papers that have performed RRA estimation for the Brazilian economy. Issler \& Piqueira (2000), find GMM estimates between 0.891 and 2.202 (median 1.70) using quarterly data with seasonal dummies and values between 2.64 e 6.82 (median 4.89) using annual data for the period 1975 to 1994 . Nakane \& Soriano (2003), estimate values for the relative risk aversion between -0.1 and 4.3 using also GMM estimation. Catalão \& Yoshino (2006), using quarterly data, obtain GMM estimates of 0.8845 and 2.119 for the period 1991 to mid 1994 (Pre Real Plan) and mid 1994 to 2003 (Post Real Plan), respectively. Also, Araujo (2005) using GMM estimation found similar ranges with a quarterly data for the period 1974 to 1999 . For constant relative risk aversion, he found a mean of 2.17 .

\footnotetext{
${ }^{5}$ In fact, the RRA parameters calculated here are negative, since all our quotes are Brazilian Reais per U.S. Dollar, i.e., we are quoting the U.S. Dollar instead of our risky asset, the Brazilian Real. In order to have the RRA for our Risky asset, the Brazilian Real, we just change the signal.
} 
In order to assess estimation robustness we made some tests. If you take out the first 12 months of the sample the RRA parameter oscillates to 2.3056 with a p-value of $15.85 \%$. When you take out the last 12 months it goes to 2.5963 with a p-value of $9.34 \%$. This shows that there is some robustness on estimated data regarding sample changes.

Another robustness exercise made was estimating 100 months rolling windows. The results are in Table 1 and again show some robustness regarding the estimation.

Table 1: Descriptive Statistics

\begin{tabular}{lr}
\hline Mean & 2.5684 \\
Standard Error & 0.0602 \\
Median & 2.6106 \\
Standard Deviation & 0.3950 \\
Variance & 0.1560 \\
Kurtosis & 1.2134 \\
Asymmetry & -0.2852 \\
Minimum & 1.6545 \\
Maximum & 3.7096 \\
\hline
\end{tabular}

\subsection{Real-World Density}

Once we have the Relative Risk Aversion parameter and the Risk-Neutral Density, we calculate the Real-World Density using the Liu et al. (2007) Parametric Risk transformation as described on section 4 . Figure 1 below shows typical distributions for our estimated RRA parameter (2.7). These are the densities on July 2006 for options expiring on August 2006. Note that the Real World Density appears on the left of the RND, and this sounds counter intuitive, since the inclusion of risk-aversion usually shifts the distribution to the right. The explanation is that we are using the exchange rate quoted as Brazilian Real per US Dollar, i.e., we are not quoting the "risk" currency, but the other currency.

We can check the differences between these two densities looking at Figure 2, which shows the difference between the Risk-Neutral and Real-World densities. We see that the RND has more mass to the right, as well as a fatter right tail.

\subsection{Density Forecast Evaluation}

In this section, we evaluate the out-of-sample performance of the Risk-Neutral and Real-World densities. For the real world densities, we need to choose a RRA parameter in order to use the risk-transformation. Although Liu et al. (2007) use their own estimates for the RRA, we consider that using the insample estimates for the RRA would make the evaluation not truly out-ofsample, since at least one parameter is estimated in-sample.

However, in fact our estimates for the RRA are pretty much in line with articles that use data samples almost entirely before the beginning of our sample. In this way, we have decided to use an RRA varying from 0 (the RiskNeutral) to 4 . 


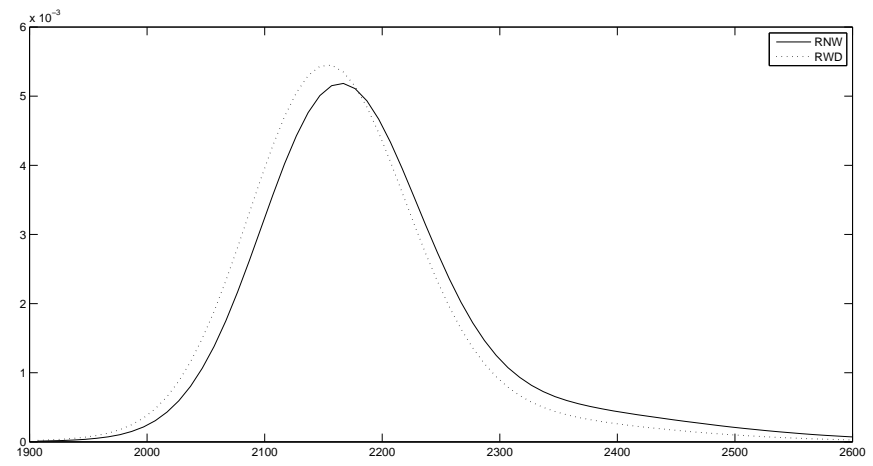

Figure 1: Risk-Neutral and Real-World Densities for July, 2006

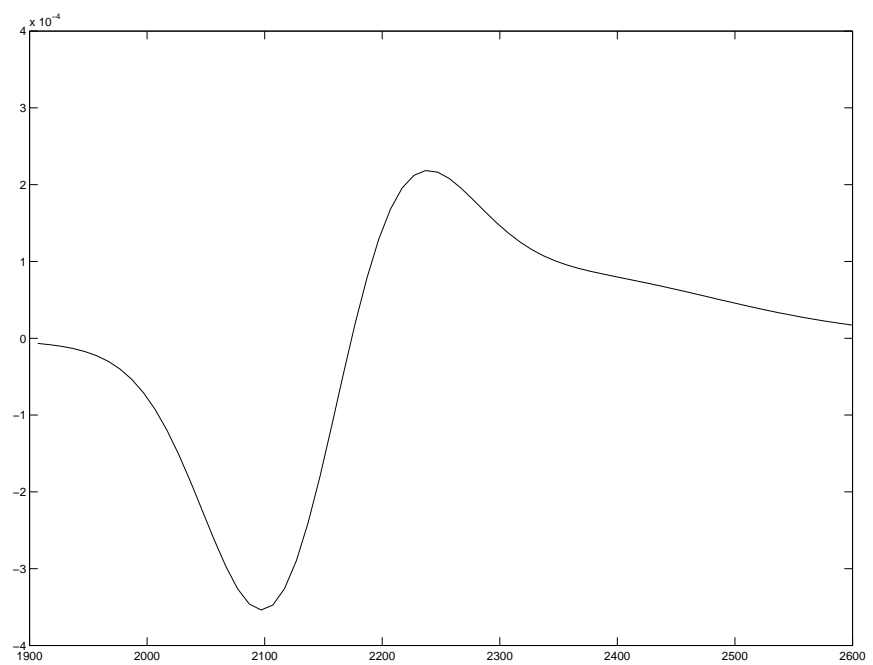

Figure 2: Risk-Neutral minus Real-World Densities

Our density forecast evaluation is based on Berkowitz (2001) and Crnkovic \& Drachman (1996) and uses the following transformation in order to generate series $U$ in the following way:

$$
U=\left\{U_{i}\right\}=\left\{\tilde{g}_{C D F}^{-1}\left(P T A X_{i+1} \mid \widehat{\theta}_{i}, c\right)\right\}
$$

If the forecast density models are good, this series $U$ must be a Uniform distribution in the range [0,1]. Berkowitz (2001) goes further and "normalize" this $U$ series using the inverse of the standard normal distribution, generating a $Z$ series:

$$
Z=\left\{Z_{i}\right\}=\left\{\Phi_{i}^{-1}\left(U_{i}\right)\right\}
$$

If the forecast density models are good, this series $Z$ should follow Standard Normal distribution. Thus, we may apply usual normality tests like 
the Kolmogorov-Smirnov in this series $Z$ in order to assess the quality of the density forecast. Berkowitz (2001) proposes a test that besides testing standard normality, also tests for first order autocorrelation in the $Z$ series. The Berkowitz Likelihood Ratio statistics must follow a $\chi_{a}^{2}$ distribution under the assumption that the density forecast model is good. Results are on Table 2:

Table 2: Goodness of fit statistics for selected RRAs

\begin{tabular}{lccccc}
\hline \multicolumn{2}{c}{ RRA } & Kolmogorov Distance & p-value & Berkowitz LR & p-value \\
\hline RND & 0.00 & 0.107 & 0.069 & 3.675 & 0.299 \\
IP1 & 0.62 & 0.096 & 0.136 & 3.126 & 0.373 \\
& 1.00 & 0.087 & 0.216 & 2.898 & 0.408 \\
& 1.50 & 0.080 & 0.302 & 2.719 & 0.437 \\
IP2 & 1.70 & 0.078 & 0.331 & 2.685 & 0.443 \\
& 2.00 & 0.073 & 0.420 & 2.675 & 0.445 \\
AR & 2.17 & 0.069 & 0.486 & 2.690 & 0.442 \\
& 2.50 & 0.064 & 0.576 & 2.762 & 0.430 \\
IS & 2.70 & 0.062 & 0.629 & 2.832 & 0.418 \\
& 3.00 & 0.057 & 0.713 & 2.978 & 0.395 \\
& 3.50 & 0.057 & 0.724 & 3.319 & 0.345 \\
& 4.00 & 0.067 & 0.525 & 3.780 & 0.286 \\
& 4.50 & 0.078 & 0.338 & 4.358 & 0.225 \\
IP3 & 4.89 & 0.085 & 0.244 & 4.887 & 0.180 \\
\hline
\end{tabular}

IP1, IP2 and IP3 satnds for Issler \& Piqueira (2000) seasonally adjusted with quarterly data, quarterly data with seasonal dummies and annual data, respectively. AR stands for Araujo (2005) and IS stands for in-sample estimation.

The RND would be rejected at $10 \%$ significance level considering the Kolmogorov distance, while the RWD would perform well, including the RRA = 2.17 estimated by Araujo (2005), which we believe is a true out-of-sample estimation for the RRA parameter, since his time period finishes near the beginning of our time period. A RRA around 3 would bring the best out-of-sample results using Kolmogorov as we can see on Figure 3.

Regarding the Berkowitz LR test, both RRA and RWD performed well and passed the test. An RRA near 2 would bring the best performance using the Berkowitz approach as we can see on Figure 3.

Overall, there is evidence that the addition of a risk premium in the RND using a risk-aversion parameter bring better results in the out-of-sample assessment.

\section{Conclusions}

We have estimated the USD/BRL option-implied Risk-Neutral Densities using the Mixture of Two Log-Normals method. We have also calculated the Relative Risk Aversion and the Real-World density, and performed an out-ofsample evaluation of the density forecast ability. This paper is the first to calculate the RRA parameter implied in option prices for an emerging market currency. Our estimated value of the RRA parameter is around 2.7, which is in line with other articles that have estimated this parameter for the Brazilian Economy, such as Araujo (2005) and Issler \& Piqueira (2000). 


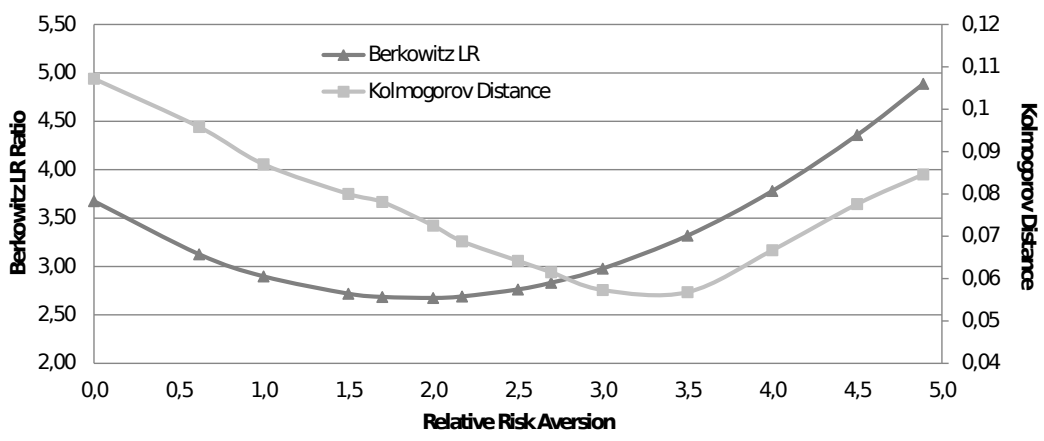

Figure 3: Density Forecast Results

Our out-of-sample evaluation results showed that the RND has some ability to forecast the Brazilian Real exchange rate. Abe et al. (2007) found also mixed results in the out-of-sample analysis of the RND forecast ability for exchange rate options. However, when we incorporate the risk aversion into RND in order to obtain a Real-world density, the out-of-sample performance improves substantially, with satisfactory results in both Berkowitz and Kolmogorov tests. Therefore, we would suggest not using the "pure" RND, but rather taking into account risk aversion in order to forecast the Brazilian Real exchange rate.

Given this good performance in the out-of-sample assessment, a suggestion for future research would be to use the Real-World Density forecasts calculated in this article for calculations of market risk and portfolio optimization. We would also suggest evaluating the use of other RND and RWD estimation methods other than the Mixture of Normals.

\section{Acknowledments}

We would like to thank an anonymous referee for comments that help to improve the present work. Any remaining errors are our own. J. Fajardo would like to thank CNPq for financial support.

\section{Bibliography}

Abe, M. M., Chang, E. J. \& Tabak, B. M. (2007), 'Forecasting exchange rate density using parametric models: The case of brazil', Brazilian Finance Review 5, 29-39.

Ait-Sahalia, Y. \& Lo, A. (1998), 'Nonparametric estimation of state-price densities implicit in financial asset prices', Journal of Finance 53, 499-547.

Araujo, E. (2005), 'Avaliando três especificações para o fator de desconto estocástico através da fronteira de volatilidade de hansen e jagannathan: Um estudo empírico para o brasil', Pesquisa e planejamento econômico 35, 49-74.

Bahra, B. (1997), Implied risk-neutral probability density functions from option prices: Theory and application. Bank of England Working Paper No 66.

URL: Available at SSRN: $h$ ttp://ssrn.com/abstract $=77429$ 
Bakshi, G., Carr, P. \& Wu, L. (2008), 'Stochastic risk premiums, stochastic skewness in currency options, and stochastic discount factors in international economies', Journal of Financial Economics 87, 132-156.

Berkowitz, J. (2001), 'Testing density forecasts, with applications to risk management', Journal of Business and Economic Statistics 19, 465-474.

Black, F. (1976), 'he pricing of commodity contracts', Journal of Financial Economics 3, 167-179.

Bliss, R. R. \& Panigirtzoglou, N. (2004), 'Option implied risk aversion estimate', Journal of Finance 59, 407-446.

Buchen, P. \& Kelly, M. (1996), 'The maximum entropy distribution of an asset inferred from option prices', Journal of Financial and Quantitative Analysis 31, 143-159.

Catalão, A. \& Yoshino, J. (2006), 'Fator de desconto estocástico no mercado acionário brasileiro', Estudos Econômicos 36, 435-463.

Crnkovic, C. \& Drachman, J. (1996), 'Quality control', Risk 9, 138-143.

Issler, J. \& Piqueira, N. (2000), 'Estimating relative risk aversion, the discount rate, and the intertemporal elasticity of substitution in consumption for brazil using three types of utility function', Brazilian Review of Econometrics 20, 200-238.

Jackwerth, J. C. (1999), 'Option-implied risk-neutral distributions and implied binomial trees: A literature review', Journal of Derivatives 7, 66-82.

Jackwerth, J. C. (2000), 'Recovering risk aversion from option prices and realized returns', Review of Financial Studies 13, 433-451.

Jackwerth, J. C. \& Rubinstein, M. (1996), 'Recovering probability distributions from option prices', Journal of Finance 51, 1611-1631.

Jondeau, E. \& Rockinger, M. (2001), 'Gram-charlier densities', Journal of Economic Dynamics and Control 25, 1457-1483.

Liu, X., Shackleton, M., Taylor, S. \& Xu, X. (2007), 'Closed-form transformations from risk-neutral to real-world distributions', Journal of Banking and Finance 31, 1501-1520.

Micu, M. (2005), Extracting expectations from currency option prices: a comparison of methods. proceedings of 11th International Conference on Computing in Economics and Finance, Washington DC, USA.

Nakane, M. \& Soriano, L. (2003), Real balances in the utility function: Evidence for brazil. Working Paper No. 68, Banco Central do Brasil.

Ross, S. (1976), 'Options and efficiency', Quarterly Journal of Economics 90, 75-89.

Rubinstein, M. (1994), 'Implied binomial trees', Journal of Finance 49, 771818.

Shimko, D. (1993), 'Bounds of probability', Risk 6, 33-37. 